\title{
UNIDADES FRASEOLÓGICAS ESPECIALIZADAS: NOVAS PERSPECTIVAS PARA SUA IDENTIFICAÇÃO E TRATAMENTO
}

\author{
Cleci Regina Bevilacqua
}

RESUMO: This paper presents Specialised Phraseologic Units, within the framework of the Terminology's Communicative Theory (TCT) proposed by Cabré (1998, 1999). First, we will briefly introduce the basic theoretic principles of this theory; we will then discuss the implications of their acceptance for the analysis and treatment of specialised phraseology. Finally, we will mention some of the consequences of this new approach for terminological research in the context of Mercosul.

PALAVRAS-CHAVE: terminologia, fraseologia especializada, unidades fraseológicas especializadas, discurso especializado, aplicações para o Mercosul.

\section{INTRODUÇÃO}

A fraseologia especializada é um tema que vem merecendo uma maior atenção por parte dos pesquisadores nos últimos anos. Em princípio, este fato estaria motivado por necessidades práticas muito concretas relacionadas à produção de textos especializados, principalmente por tradutores e redatores.

Um dos problemas com o qual se defrontam estes profissionais é o uso correto de Unidades Fraseológicas Especializadas (UFE), entendidas como unidades sintagmáticas que incluem um termo entre seus elementos, que possuem um determinado grau de fixação e uma frequiência relevante em um conjunto de textos ou em um âmbito especializado. Como exemplos podemos mencionar instaurar um inquérito, cometer um delito, clicar o mouse, proteção do meio ambiente, captação de energia ${ }^{l}$, etc. Reconhecer e saber utilizar estas unidades assegura a produção de textos corretos do ponto de vista lingüístico e adequados do ponto de vista especializado.

Além deste tipo de unidades, que na realidade se identificam com sintagmas verbais e nominais ${ }^{2}$, pode-se considerar como fraseológicas as unidades mais próximas a fórmulas ou frases próprias de determinados discursos como o administrativo e o jurídico, como, por exemplo, esta lei entra em vigor na data de sua publicação; desde já, agradecemos a atenção dispensada, etc.

Neste trabalho, nos centramos especificamente no primeiro tipo de unidades, ou seja, as unidades fraseológicas consideradas como sintagmas e, levando em conta os resultados apresentados em Bevilacqua (1999), as definimos como unidades sintagmáticas de significação especializada que incluem um elemento eventivo (verbal o procedente de verbo) e, no mínimo, uma unidade terminológica. Além disso, possuem certo grau de fixação, determinado mais pela relação semântica estabelecida entre os elementos que as compõem que pelas relações sintáticas, e uma freqüência relevante em determinado âmbito ou nos textos especializados em que são utilizadas.

Como exemplos dessas unidades podemos mencionar consumir energia, transformar a energia solar em energia calorífica, captação de energia, armazenamento de energia solar, energia captada, energia consumida ${ }^{3}$, etc.

Cleci Regina Bevilacqua é professora do Instituto de Letras da UFRGS

${ }^{1}$ Nem sempre há um consenso em relação ao status fraseológico das unidades nominais deverbais, já que há autores que as consideram termos e outros, unidades fraseológicas. Do nosso ponto de vista, o caráter fraseológico dessas unidades está determinado por vários fatores entre os quais podemos mencionar a lexicalização.

${ }^{2}$ Há autores que consideram como fraseológicos também os sintagmas adjetivais, adverbiais e preposicionais.

${ }^{3}$ Em Bevilacqua (1999), se estabelece uma graduação de mais a menos fraseológica para estas unidades. Assim, as unidades cujo núcleo sintático é um verbo (captar enegia) são consideradas unidades fraseológicas especializadas e se situam no extremo de maior Organon, Porto Alegre, nº 26, 1998 
Distinguimos estas unidades de outras unidades sintagmáticas como as Unidades Terminológicas Poliléxicas (UTP) ${ }^{4}$ e as unidades livres. As UTP são basicamente nominais, possuem caráter denominativo e valor referencial e representam um nó de conhecimento na estruturação conceptual de um âmbito especializado (energia nuclear, energia eólica).

Por sua vez, as unidades livres, embora possam ter estruturas sintáticas semelhantes às UFE, possuem um grau nulo de fixação e uma frequiência mínima (definir a energia solar, apostar pela energia nuclear).

No entanto, identificar estas unidades e diferenciá-las de outras possíveis unidades sintagmáticas como as próprias UTP e as unidades livres é uma tarefa complexa. Em certa medida, esta dificuldade deve-se ao fato de que os textos especializados refletem partes de conhecimento representados não somente por termos, mas também por outras unidades que, combinadas com aqueles podem originar distintas unidades portadoras de conhecimento especializado. Deste modo, é possível ter diferentes unidades lingüísticas especializadas tanto por sua forma (combinação de nome e adjetivo, verbo e nome, nome deverbal e nome, etc.) como por seu conteúdo, uma vez que podem concentrar um determinado significado especalizado em maior o menor grau, podem estar mais ou menos lexicalizadas, etc. São, portanto, unidades diversas, mas com propriedades muito próximas que são de ordem diferenciada (morfológica, sintática, semântica, pragmática) e cada tipo de unidade pode possuir algumas destas propriedades ou todas em graus diferentes. Daí a dificuldade de reconhecê-las e de distingui-las.

$\mathrm{Na}$ tentativa de identificar as UFE, surgem, principalmente a partir da década de 80, várias propostas que pretendem estabelecer, por um lado, uma definição para estas unidades e, por outro, os critérios para seu reconhecimento. Estas propostas pretendem, basicamente, identificar a fraseologia de determinados âmbitos, tendo em vista a produção de textos especializados, atendendo, assim, a determinadas necessidades práticas, como afirmamos anteriormente. Como este é um objetivo amplo, os critérios para seu reconhecimento são bastante diversificados, resultando em tipos muito diferenciados de unidades consideradas como $\mathrm{UFE}^{5}$.

No entanto, acreditamos que estas questões de ordem prática não parecem ser a única razão que justifique o interesse pelo estudo da fraseologia especializada. Do nosso ponto de vista, este interesse também esta motivado pelo surgimento de novas propostas teóricas para a terminologia de caráter comunicativo e cognitivo. A partir do momento em que se começa a enfocar a terminologia da perspectiva sociolingüística (escola quebequense), da perspectiva comunicativa (CABRÉ 1998a e b e 1999 a, b e c) e da perspectiva socio-cognitiva (TEMMERMAN, 1999), propostas surgidas basicamente da constatação da insuficiência dos pressupostos e princípios da Teoria Geral da Terminologia (TGT) ${ }^{6}$, ampliam-se, por um lado, os tipos de unidades que constituem o objeto de estudo da terminologia, entre as quais se incluem as UFE, e, por outro, os aspectos a serem descritos em relação a estas unidades.

Neste trabalho, entre estas perspectivas, optamos especificamente pela inicialmente denominada Teoria Comunicativa da Terminologia (TCT), proposta por Cabré (1998a e b e 1999a, b e c), porque consideramos que somente uma teoria que leve em conta não apenas os aspectos lingüísticos, mas também os comunicativos e cognitivos, e que, além disso, tome o texto como base de análise, pode dar conta do carácter essencialmente discursivo das UFE.

Tomando como base este marco teórico, apresentaremos inicialmente seus pressupostos; em seguida comentaremos suas implicações para o estudo da fraseologia em geral e, finalmente, as conseqüências que pressupõe a análise da fraseologia especializada a partir desta perspectiva para a pesquisa terminológica desenvolvida no âmbito do Mercosul.

\section{A TEORIA COMUNICATIVA DA TERMINOLOGIA E SUAS IMPLICAÇÕES NO ESTUDO DA FRASEOLOGIA ESPECIALIZADA}

Entre os pressupostos básicos da TCT podemos mencionar os seguintes:

\footnotetext{
graduação fraseológica. Por sua vez, as unidades formadas por un núcleo sintático nominal e um particípio adjetivo (energia captada) estariam em uma posição intermediária, enquanto que as unidades formadas por un núcleo sintático nominal deverbal (armazenameto de energia) tendem a estar no extremo de menor graduação fraseológica e, portanto, mais próximos aos termos. Para comprovar o caráter fraseológico desses dois últimos tipos de unidades é necessário levar em conta aspectos como seu grau de lexicalização, o grau de concentração de significado especializado, etc.

${ }^{4}$ As Unidades Terminológicas (UT) podem ser monoléxicas ou poliléxicas, conforme proposta de Estopà (1999) apud David (1993). Neste trabalho, para referir-nos às unidades terminológicas poliléxicas utilizaremos a abreviatura UTP.

5 Para uma revisão das definições de UFE, de sua delimitação em relação a outras unidades sintagmáticas e dos critérios para seu reconhecimento, ver Bevilacqua 1996 e 1999.

${ }^{6}$ Ver Wüster (1998) e Cabré (1996).
} 
- é uma perspectiva lingüística que incorpora, além de uma teoria da língua, uma teoria do conhecimento e uma teoria da comunicação;

- concebe a língua como um sistema que inclui gramática, semântica e pragmática;

- considera os textos ou os discursos especializados como base da comunicação especializada e, portanto, estes discursos fazem parte da língua natural e não constituem sublinguagens diferenciadas daquela, embora incluam unidades de outros sistemas simbólicos;

- considera o texto como âmbito natural das Unidades de Significação Especializada, o que permite uma descrição mais ampla das unidades terminológicas bem como de outras unidades de significação especializada (verbos, adjetivos e adverbios, unidades fraseológicas especializadas e as combinações especializadas freqüentes);

- considera as Unidades de Significação Especializada como unidades que são ao mesmo tempo lingüísticas, cognitivas e comunicativas.

- considera que as Unidades de Significação Especializada são, em princípio, unidades léxicas que fazem parte do léxico do falante e que adquirem valor especializado de acordo com seu uso em determinado âmbito especializado;

- permite, a partir de sua conformação interdisciplinar, o tratamento multidimensional e multifuncional das Unidades de Significação Especializada ${ }^{7}$;

- admite a variação conceptual e denominativa das Unidades Terminológicas, levando em conta a dimensão comunicativa e discursiva dessas unidades.

Se consideramos estes pressupostos, podemos observar que a TCT comporta não somente uma teoria da linguagem, mas também uma teoria comunicativa e uma teoria cognitiva que permite analisar as unidades de significação especializada a partir de qualquer uma dessas perspectivas.

No que diz respeito especificamente às UFE, acreditamos que estas perspectivas distintas são importantes porque:

- a perspectiva cognitiva que incorpora permite investigar a forma como reconhecemos e adquirimos o conhecimento especializado através das unidades que transmitem esse conhecimento e que não são exclusivamente termos;

- a perspectiva social permite tratar e descrever a fraseologia especializada, levando em conta os aspectos relacionados às diferentes situações comunicativas (emissor, destinatário, função dos textos especializados, etc.) que influem na conformação e uso dessas unidades;

- a perspectiva lingüística permite descrever suas propriedades considerando de forma conjunta todos os aspectos lingüísticos (gramaticais, semânticos e pragmáticos).

Para as considerações que fazemos neste trabalho, nos situamos nesta última perspectiva.

Outro aspecto importante é a amplição das unidades que podem ser consideradas como objeto de estudo da terminologia. Nesse sentido, não apenas as unidades terminológicas, definidas por esta teoria como unidades nominais, de caráter denominativo e função referencial, são consideradas como unidades transmissoras de conhecimento especializado, mas também outras unidades lingüísticas podem exercer esta função.

Em conjunto, estas unidades são denominadas de Unidades de Significação Especializada (USE) e podem ser definidas como unidades portadoras de conhecimento especializado, linguiísticas ou não lingüísticas (símbolos, fórmulas), que se usam em situações de comunicação especializada. Entre as USE lingüísticas encontram-se as unidades léxicas nominais, prototipicamente as Unidades Terminológicas (UT) próprias de um âmbito especializado, unidades verbais, adjetivais e adverbiais, e unidades poliléxicas, entre as quais se incluem as UFE e as combinações especializadas recorrentes. Este conjunto de unidades pode ser agrupado da forma que apresentamos a seguir, tomando como base o esquema proposto por Estopà $(1999)^{8}$ :

1. USE lingüísticas que podem ser:

1.1 USE léxicas

- nominais (UT)

- adjetivais

- verbais

- adverbiais

1.2 USE não léxicas

- unidades fraseológicas especializadas

\footnotetext{
${ }^{7}$ A multidimensionalidade diz respeito à variação, à polidricidade, isto é, à possibilidade de uma mesma unidade ser tratada a partir de diferentes pontos de vista e à dinamicidade das USE, enquanto que a multifuncionalidade se refere às funções representativa $\mathrm{e}$ comunicativa dessas unidades.

${ }^{8}$ Para mais detalhes referentes a classificação das Unidades de Significação Especializada, ver Estopà (1999:287).

Organon, Porto Alegre, n' 26, 1998 
- $\quad$ combinações recorrentes $^{9}$

2. USE não lingüísticas:

- símbolos

- nomes científicos em latim

- fórmulas.

Observe-se, portanto, a inclusão do estudo das UFE dentro do âmbito da terminologia. Esta posição que parece evidente dada a estreita relação dessas unidades com os termos, pelo menos na definição que propomos para as mesmas, nem sempre é unânime entre os vários estudiosos que tratam este tema. É possível encontrar autores (BÈJOINT e THOIRON, 1992; PICHT, 1990) que defendem o estudo da fraseologia especializada como uma disciplina independente da terminologia.

Do ponto de vista do qual partimos, consideramos que seu estudo dentro do âmbito da terminologia é importante pelas razões que mencionamos a seguir e que são resultantes dos próprios pressupostos apresentados pela TCT.

As UFE são unidades formadas por uma unidade terminológica, no mínimo, e por coocorrentes desta unidade. Estes elementos não coocorrem casualmente num texto, senão que entre eles se estabelecem determinadas relações sintácticas e sobretudo semânticas que permitem recolhecê-las como unidades estáveis, que possuem determinado grau de fixação e que são freqüentes em determinado âmbito.

Levando em conta as relações estabelecidas entre estes elementos, se deduzem dois fatos que podem ter consequiências importantes não apenas para a fraseologia, mas também para a pesquisa terminológica e que devem ser ainda pesquisados.

O primeiro deles é que a partir do reconhecimento das UFE, seria possível identificar as unidades coocorrentes de um termo. Deste modo, se tomamos como exemplo as UFE recolhidas de textos sobre energia solar como aproveitar energia, acumular energia, armazenar energia, captar energia, consumir energia, converter energia, gerar energia, produzir energia e utilizar energia, podemos identificar a série de coocorrentes do termo energia: aproveitar, acumular, produzir, armazenar, gerar, captar, converter, consumir ${ }^{10}$.

Poderia-se afirmar, então, que estes co-ocorrentes formam uma constelação em torno a uma determinada unidade terminológica, muitos dos quais podem ocorrer também com outros termos como eletricidade, calor, etc. Formariam, assim, uma grande rede de relações entre as diferentes USE como mostramos a seguir:

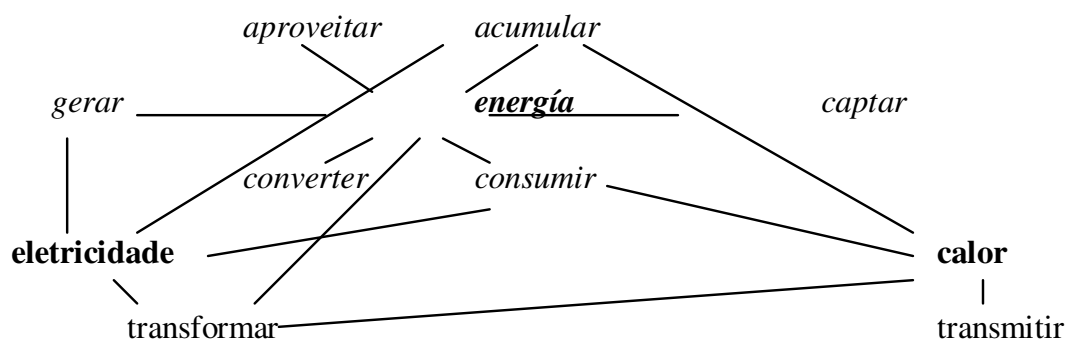

figura 1

Esta rede permitiria, em primeiro lugar, ajudar a identificar outras possíveis USE que, no caso dos exemplos apresentados são verbos, mas que poderiam ser adjetivos, advérbios ou preposições (Exemplo: ambientalmente nocivo, etc.). Em segundo lugar, poderia ser útil na elaboração da estrutura conceptual de um âmbito determinado ou referente a um texto ou conjunto de textos especializados e, finalmente, serviria de base para identificar as relações semânticas estabelecidas entre os termos e seus coocorrentes.

Se a partir das UFE podemos chegar às demais USE e às relações estabelecidas entre ellas, o segundo fato vai no sentido inverso a este, ou seja, a partir da elaboração dessas redes e da identificação das relações entre as unidades que as compõem, pode-se prever as possíveis UFE próprias de um âmbito. Por exemplo, a partir de produzir e energia, se chegaria a unidade produzir energia, cujo caráter

\footnotetext{
${ }^{9}$ Estopà (1999) afirma que estas unidades estão formadas por um núcleo (nominal) e um complemento que são USE, mas que a unidade em seu conjunto não forma um termo. Cita como exemplo, radiografia del tòrax, diganòstic de mononucleosi infecciosa.

${ }^{10}$ Embora apresentamos os exemplos unicamente em sua forma verbal, estas formas também podem manifestar-se superficialmente por nomes deverbais (aproveitamento, armazenamento, produção, etc.) e por adjetivos participios (acumulada, captada, consumida, etc.). Para mais detalhes sobre estas unidades, ver Bevilacqua (1999) e também as observações feitas na nota 3.

Organon, Porto Alegre, n 26, 1998$$
\text { Organon, Porto Alegre, nº 26, } 1998
$$ 
fraseológico teria de ser atestado ou comprovado pela aplicação de outros critérios (grau de fixação, freqüência, etc).

Estas relações poderiam servir também como um fator a mais a ser considerado no estabelecimento do grau de fixação das próprias UFE, posto que seria possível determinar o alcance semântico dessas unidades. Em outas palabras, seria possível identificar se uma UT pode combinar-se com um número reduzido de coocorrentes (cometer um delito, julgar um delito) ou um número maior de coocorrentes (ligar a televisão, o aparelho de som, o rádio, o computador, etc.), do mesmo modo que um coocorrente pode combinar-se com mais de uma UT (produzir energia, produzir eletricidade, produzir calor).

Abrem-se, assim, novas perspectivas para o tratamento da fixação das UFE. Até o momento, sua fixação tem sido determinada pela frequiência (uso elevado em determinado âmbito ou textos especializados) ou pela aplicação de testes de comutação e inserção dos elementos que a formam e de transformação.

Embora sejam dois parâmetros importantes na detecção das UFE, consideramos que a freqüência é um critério aleatório que depende de outros fatores como o tamanho e o tipo de corpus utilizado como fonte de coleta dessas unidades e deve, portanto, ser definido segundo as especificidades de cada trabalho.

Por sua vez, a aplicação dos testes de comutação, inserção e transformação normalmente não leva em conta outros fatores que podem condicionar a conformação das UFE como é o caso do nível de especialização dos textos. Nesse sentido, é possível constatar que um texto de maior nível de especialização utiliza UFE que admitem menor inserção e comutação dos seus elementos, ou seja, contém UFE que admitem uma menor variação, enquanto que nos textos de menor nível de especialização tanto a inserção como a comutação são maiores e, portanto, suas UFE admitem uma maior variação ${ }^{11}$.

Além dos aspectos mencionados anteriormente, acreditamos que a detecção e o tratamento das UFE pode servir para identificar a variação conceptual e denominativa das UT, na medida em que auxilia a delimitar seu significado, não apenas em âmbitos distintos, mas também dentro de uma mesma área.

Outro dos pressupostos da TCT é considerar os discursos especializados como base da comunicação especializada e como âmbito natural em que ocorrem as USE, o que permite tratar estes discursos como parte da linguagem natural e não como linguagem artificial e, em consequiência, descrever as USE, e portanto as UFE, levando em conta todos os aspectos lingüísticos (gramaticais, semânticos e pragmáticos).

Embora a aplicação conjunta de todos aspectos linguísticos para a identificação e o tratamento das UFE pareça óbvia, uma análise das propostas feitas até o momento permite afirmar que, em geral, não são considerados globalmente e mais freqüentemente são aplicados em grandes blocos isolados.

Assim, é possível identificar propostas que aplicam aspectos ou critérios exclusivamente sintáticos, principalmente relacionados aos padrões sintáticos e ao grau de fixação sintática (BLAIS, 1993; LAINÉ, 1993); outras aplicam critérios pragmáticos relacionados à freqüência e ao caráter prototípico de determinadas unidades em um âmbito específico ou tipo de discurso (ROBERTS, 1993; GOUADEC, 1994; PARC, 1993). Poucas são as propostas que associam os apectos sintáticos e semânticos (PAVEL, 1993; LAPORTE e L'HOMME, 1997) e raramente se vê refletido o conjunto desses aspectos para o reconhecimento e descrição das UFE (HEID, 1998).

Observamos ainda que os aspectos pragmáticos são os que condicionam o valor especializado que adquirem as UFE. Em outras palavras, seu caráter de unidade transmissora de conhecimento especializado está condicionado pelas diferentes situações comunicativas (objetivo e destinatários do texto especializado, nível de especialização, perspectiva a partir da qual se trata determinado tema, etc.) que caracterizam determinado discurso especializado. Estes aspectos também se relacionam ao grau de fixação dessas unidades e ao seu uso nos textos especializados, conforme já afirmamos anteriormente.

Com base nas afirmações feitas, acreditamos que uma proposta satisfatória para o reconhecimento e descrição das UFE deve incluir todos os critérios referidos anteriormente e, sobretudo, deve relacionar os critérios sintáticos e semânticos aos pragmáticos. Acreditamos que somente com uma proposta deste tipo é possível tratar aspectos ignorados até o momento em relação às UFE e que permitirão dar conta de sua complexidade e, ao mesmo tempo, estabelecer parâmetros para reconhecê-las e diferenciá-las de outras USE sintagmáticas.

Sabemos, contudo, que para chegar a estes resultados, é necessário ainda uma descrição mais aprofundada das UFE de vários âmbitos que leve em conta todos os aspectos referidos, fato que converte a fraseologia especializada em um tema rico que ainda possui muitos aspectos a serem explorados.

${ }^{11}$ Estes dados podem ser conferidos em Bevilacqua (1999). 


\section{A FRASEOLOGIA ESPECIALIZADA E A PESQUiSA TERMINOLÓGICA NO ÂMBITO Do MERCOSUL}

Se até o momento, mencionamos algumas implicações da TCT para o estudo da fraseologia especializada, que de modo algum se esgotam nos aspectos apresentados acima, consideramos importante apresentar algumas de suas conseqüências e também algumas razões que justificam seu estudo no âmbito da pesquisa terminológica desenvolvida no contexto do MERCOSUL.

A criação desse mercado como uma nova área de intercâmbio econômico, científico e cultural gerou, em relação à terminologia, duas necessidades importantes. Uma primeira necessidade refere-se à elaboração de produtos terminológicos bilíngües que dêem conta das terminologias utilizadas para consolidar o intercâmbio entre os vários países que conformam este novo mercado. A segunda, diz respeito ao desenvolvimento da pesquisa terminológica tanto em relação aos aspectos teóricos como aos aplicados para a elaboração desses produtos e que deve levar em conta as especificidades de cada um dos países, além das consequiências resultantes dessa integração e que interferem no trabalho terminológico (delimitação dos âmbitos especializados, identificação dos termos, estabelecimento de definições e de equivalentes, etc.).

No que se refere à elaboração de produtos terminográficos, ressaltamos que são principalmente glossários e dicionários que partem do português ou do espanhol com seus equivalantes correspondentes em uma dessas línguas e, muitas vezes, também em inglês por ser considerada uma língua franca. As temáticas às quais se referem se relacionam aos âmbitos jurídico, administrativo e científico e aos setores de comércio e da indústria, áreas implicadas mais diretamente no processo de integração.

No que diz respeito especificamente à fraseologia especializada, é possível constatar que seu estudo é ainda incipiente nos vários centros que desenvolvem a pesquisa terminológica. Além disso, essas construções não têm sido incluída nas obras terminográficas.

Consideramos, portanto, que a inclusão desse tema como parte da pesquisa terminológica e sua representação nos produtos terminográficos elaborados para atender a demanda específica gerada por este novo contexto constitui-se, por si só, um aspecto inovador ${ }^{12}$.

Seu estudo nesse contexto pode justificar-se ainda por razões de ordem prática e teórica, como as que mencionaremos a seguir, além das já apresentadas anteriormente para a fraseologia especializada em geral.

Ao considerar que uma necessidade básica decorrente dessa integração e dessa nova realidade é a identificação e, de certo modo, a fixação de terminologias que ainda não estavam formalmente recolhidas e registradas para o português e o espanhol, acreditamos que a identificação e o tratamento das UFE são importantes porque:

- $\quad$ podem ajudar não só a coletar e a delimitar o significado dos termos em determinado âmbito e em âmbitos distintos, mas também a estabelecer seus equivalentes nas duas línguas oficiais do MERCOSUL;

- podem auxiliar, ainda que de forma indireta, na elaboração da estrutura conceptual dos diferentes âmbitos, uma vez que, juntamente com as UT, se referem às ações, processos e resultados próprios destes âmbitos, correspondendo, portanto, outras unidades de significação conforme indicamos no esquema apresentado anteriormente;

- $\quad$ podem ser uma ferramenta para a identificação da variação denominativa e conceptual dos termos e, de certo modo, também das demais USE.

Em relação a este último ponto, a contribuição do estudo das UFE pode ser ainda mais importante, se consideramos as diferentes perspectivas a partir das quais se enfoca cada âmbito não somente em cada um dos quatro países, mas também entre os diferentes países, uma vez que cada realidade em particular, cada cultura com suas idiossincrasias, pode determinar e atribuir significados diferenciados para um mesmo termo ou uma mesma USE.

Consideramos que as razões mencionadas até aqui reforçam a adoção da perspectiva da TCT, uma vez que é uma teoria flexível que pode ser adaptada às necessidades de cada pesquisa ou trabalho terminológicos elaborados para atender determinadas necessidades geradas por realidades muito diferenciadas. Esta flexibilidade permite tratar a diversidade e, portanto, a variação lingüística refletida nos discursos especializados elaborados nesses diferentes contextos sociais.

\footnotetext{
12 Ainda que seja um tema amplamente estudado nos últimos anos, este estudo raramente se vê refletido nos trabalhos práticos elaborados em outros países. Pode-se destacar trabalhos levados a cabo na Universidade de Rennes II dirigidos por Daniel Gouadec ou vocabulários fraseológicos publicados pelo Réseau International de Néologie (RINT), Canadá, de autoria de Claude Lainé (1993) e de Silvia Pavel e Monique Boileau (1993).
} 
Se as razões anteriores são de caráter mais teórico, embora também se relacionam aos aspectos aplicados da terminologia, não podemos deixar de mencionar as conseqüências mais práticas decorrentes do estudo da fraseologia especializada no âmbito do MERCOSUL. Nos referimos especificamente à importância de sua representação em produtos terminográficos, uma vez que é uma informação essencial para a elaboração de textos especializados. Este fato ganha maior importância se levamos em conta, por um lado, a necessidade de produção de textos sobre temáticas cuja terminologia não está totalmente estabelecida e muito menos sua fraseologia e, por outro, a produção de textos nas suas duas línguas oficiais.

Essa necessidade de produção de textos nas duas línguas ou de suas traduções leva a outro tema pouco explorado até o momento, qual seja, a perspectiva bilíngüe da fraseologia especializada ${ }^{13}$ que, por si só, é um tema complexo, principalmente no que se refere ao estabelecimento de seus equivalentes.

Além desses aspectos de representação e de equivalência, na medida em que consideramos importante a inclusão da fraseologia especializada em produtos terminográficos, é necessário também repensar os formatos de registro das unidades de significação especializadas. Até o momento, os formatos propostos incluem exclusivamente informação referente às UT. No entanto, dadas as conseqüências que pressupõe a TCT e as necessidades geradas para cada trabalho em particular, faz-se necessário propor um formato diferenciado que inclua também informação referente às UFE e as demais USE e que, ao mesmo tempo, possa dar conta das relações estabelecidas entre estas unidades.

Nesse sentido, a utilização de recursos informáticos na elaboração de obras em formatos eletrônicos permite uma representação mais adequada das UT e das UFE, uma vez que é possível estabelecer vínculos e relações entre estas unidades e as informações relacionadas a elas. Por exemplo, é possível criar vínculos destas unidades com seus contextos remetendo diretamente aos textos nos quais ocorrem ou ainda estabelecer vínculos entre os formatos que registram informação terminológica e os que trazem informação fraseológica, etc.

Finalmente, gostariamos de mencionar que, pelos aspectos referidos aqui, é evidente que o estudo da fraseologia especializada também se relaciona à pesquisa sobre os discursos especializados, e o aprofudamento de seu estudo pode trazer importantes contribuições para esta área de estudo.

De todas as afirmações feitas anteriormente, podemos dizer que a fraseologia especializada é um tema que ainda tem muitos aspectos a serem explorados, principalmente se consideramos os novos paradigmas teóricos propostos para a terminologia e, particularmente, a TCT.

Neste trabalho, enumeramos alguns desses aspectos, enfatizando sua importância tanto para a pesquisa fraseológica em geral como para a fraseologia utilizada em contextos econômicos e culturais específicos. Estes aspectos são indicadores da continuidade da pesquisa sobre este tema e seus resultados devem, por sua vez, contribuir em muito para o desenvolvimento da própria teoria terminológica.

\section{BIBLIOGRAFIA}

BÉJOINT, Henri; THOIRON, Philippe. Macrostructure et microstructure dans un dictionnaire de collocations en langue de spécialité.In: Terminologie et traduction, Bruxelas, n.2-3, 1992.

BEVILACQUA, Cleci R. A fraseologia jurídico-ambiental. [Dissertação de Mestrado] Porto Alegre: Universidade Federal do Rio Grande do Sul, Curso de Pós-Graduação em Letras, 1996.

BEVILACQUA, Cleci R. Unidades Fraseológicas Especializadas: estado de la cuestión y perspectivas. [Trabalho de Pesquisa]. Barcelona, Universitat Pompeu Fabra, Institut Universitari de Lingüística Aplicada, 1999.

BLAIS, Esther. La phraséologie. Une hypothèse de travail. In: Terminologies Nouvelles, Bruxelas, n. 10, dez. 1993.

CABRÉ, Teresa; LORENTE, Mercè; ESTOPÀ, Rosa. Terminología y fraseología. In: Actas del V Simposio de Terminología Iberoamericana, Ciudad de México, nov. 1996.

CABRÉ, Teresa (org.). Terminologia. Selecció de textos d'E. Wüster. Barcelona: Universitat de Barcelona, Servei de Llengua Catalana, 1996.

CABRÉ, Teresa. Elementos para una teoría de la terminología: hacia un paradigma alternativo. In: Lenguaraz, Buenos Aires, vol. 1, 1998a.

CABRÉ, Teresa. Una nueva teoría de la terminología: de la denominación a la comunicación. In: VI Simposio de la Red Iberoamericana de Terminología. La Habana, nov. 1998b. (no prelo)

\footnotetext{
${ }^{13}$ Desmet (1995-1996) desenvolve um trabalho importante em relação à fraseologia bilíngüe, especificamente do português e do
} francês. 
CABRÉ, Teresa. Principios teóricos sobre la terminología, ámbito y unidades de estudio. Sumario de principios y consecuencias metodológicas. In: La terminología científico-técnica: reconocimiento, análisis y extracción de información formal y semántica. (Informe DGES PB-96-0293). Barcelona, Universitat Pompeu Fabra, Institut Universitari de Lingüística Aplicada, 1999a.

CABRÉ, Teresa. Variació per tema. El discurs especialitzat o la variació funcional determinada per la temática: noves perspectives. In: Caplletra: Revista Internacional de Filología, Valencia, n. 25, 1999b.

CABRÉ, Teresa. Terminología: Representación y comunicación. Una teoría de base comunicativa y otros artículos. Barcelona: Universitat Pompeu Fabra, Institut Universitari de Lingüística Aplicada, 1999c. (Sèrie Monografies, 3)

DESMET, Isabel. Pour une approche terminologique des sciences sociales et humaines. Les sciences sociales et humaines du travail en portugais et en français. [Tesis doctoral] Paris: Université Paris-Nord (Paris XIII), 1995-1996.

ESTOPÀ, Rosa. Extracció de terminologia: elements per a la construcció d'un SEACUSE (Sistema d'Extracció Automàtica de Candidats a Unitats de Significació Especialitzada). [Tesis doctoral] Barcelona: Universitat Pompeu Fabra, Institut Universitari de Lingüística Aplicada, 1999.

GOUADEC, Daniel. Nature et traitement des entités phraséologiques. In: GOUADEC, Daniel (org.) Terminologie et phraséologie. Acteurs et amenageurs. Paris: La Maison du Dictionnaire, 1994.

HEID, Ulrich. Towards a corpus-based dictionary of German noun-verb collocations. In: FONTENELLE, Thierry [org.]. Euralex'98 Proceedings, Liège, Vol II. 1998.

LAINÉ, Claude. Vocabulaire combinatoire de la CFAO mécanique. Canadá: Réseau International de Néologie, 1993.

LAPORTE, Isabelle; L'HOMME, Marie.-Claude. Recensement et consignation des combinaison lexicales en langue de spécialité: exemple d'application dans le domaine de la pharmacologie cardiovasculaire. Terminologies Nouvelles, Bruxelas, n. 16, 1997.

L'HOMME, Marie-Claude. Caractérisation des combinaisons lexicales spécialisées par raport aux collocations de langue générale. In: FONTENELLE, Thierry. [org.]. Euralex'98 Proceedings, Liège, Vol. II, 1998.

LORENTE, Mercè; BEVILACQUA, Cleci R.; ESTOPÀ, Rosa. El análisis de la fraseologia especializada mediante elementos de la lingüística actual. In: Actas VI Simposio de la Red Iberoamericana de Terminología. La Habana, noviembre de 1998. (no prelo)

PARC, Françoise. Traitement de la phraséologie terminologique tirée des textes législatifs et réglementaires suisses. In: Terminologies Nouvelles, Bruxelas, n. 10, p. 115-119, dez. 1993.

PAVEL, Silvia; BOILEAU, Monique. Vocabulary of Dynamical Systems and Fractal Imagery. Canada: Translation Bureau, 1994.

PAVEL, Silvia. La phraséologie en langue de spécialité. Méthodologie de consignation dans les vocabulaires terminologiques.In: Terminologies Nouvelles, Bruxelas, n. 10, dez. 1993.

PICHT, Heribert. LSP phraseology from the terminological point of view. In: Terminology science \& research, Viena, vol. 1, n. 1-2, 1990.

ROBERTS, Roda. Identifying the phraseology of languages for special purposes (LSPs). In: Alfa, Canada, vol. 7/8, 1995.

TERCEDOR SÁNCHEZ, María I. La fraseologia en el lenguaje biomédico: análisis desde las necesidades del traductor. [Tesis doctoral] Granada: Universidad de Granada, 1998.

TEMERMANN, Rita. Terminology: the socio-cognitive approach. In: II Simposio Internacional de Terminología. Barcelona: Universitat Pompeu Fabra, Institut Universitari de Linguiística Aplicada, jul. 1999. (no prelo)

WÜSTER, Eugen. Introducción a la teoría general de la terminología y a la lexicografía terminológica. Barcelona: Universitat Pompeu Fabra, Institut Universitari de Lingüística Aplicada, 1998. 